\title{
El COVID-19 y la protección social de los grupos pobres y vulnerables en América Latina: un marco conceptual
}

\author{
Nora Lustig y Mariano Tommasi
}

\section{Resumen}

La crisis causada por la pandemia de la enfermedad por coronavirus tiene efectos nefastos en las sociedades latinoamericanas. Los sectores más vulnerables de la sociedad, especialmente los que viven en la pobreza extrema, son los más afectados. Este artículo indica estrategias y respuestas específicas para i) reducir los riesgos epidemiológicos para salvar vidas; ii) proteger los medios de subsistencia, y iii) garantizar la acumulación de capital humano. Las externalidades epidemiológicas y las preocupaciones de carácter humanitario exigen una inclusión social universal. Para proteger la vida, la salud, los medios de subsistencia y el capital humano de los pobres y vulnerables, será fundamental realizar intervenciones específicas y decisivas a nivel local que vayan más allá de las transferencias de efectivo; destinar recursos adecuados a financiar las medidas de apoyo a los ingresos y otras intervenciones clave, e involucrar a los actores locales y las organizaciones de base para que las intervenciones sean eficaces.

\section{Palabras clave}

COVID-19, virus, epidemias, aspectos sociales, seguridad social, pobreza, personas socialmente desfavorecidas, ingresos, salud, educación, condiciones sociales, política social, América Latina

\section{Clasificación JEL}

C63, D31, I32, 138

\section{Autores}

Nora Lustig es Profesora Samuel Z. Stone de Economía de América Latina en el Commitment to Equity Institute (CEQI) de la Universidad de Tulane (Estados Unidos). Correo electrónico: nlustig@tulane.edu.

Mariano Tommasi trabaja en el Centro de Estudios para el Desarrollo Humano $(\mathrm{CEDH})$ de la Universidad de San Andrés (Argentina). Correo electrónico: tommasi@ udesa.edu.ar. 


\section{Introducción ${ }^{1}$}

La pandemia mundial de enfermedad por coronavirus (COVID-19), junto con las respuestas nacionales y extranjeras, ha afectado gravemente a la sociedad en su conjunto en términos de pérdidas económicas y de vidas. Incluso si América Latina se hubiera salvado milagrosamente de la pandemia, los sucesos externos adversos (disminución de la demanda de exportaciones y turismo, caída de los precios de las materias primas y salidas de capital sin precedentes) habrían perjudicado significativamente a los países de la región. La pandemia y las medidas diseñadas para contenerla agravan el impacto negativo producido en el nivel de vida de maneras que aún se están evaluando, dada la incertidumbre sobre la dinámica de la pandemia.

Aunque todos los niveles de la sociedad se han visto afectados, la intensidad de la repercusión varía muchísimo entre los grupos sociales. La pandemia empobrece aún más a los pobres y exacerba la desigualdad. Los trabajadores del sector informal se ven gravemente afectados por las medidas de confinamiento. Los trabajadores poco cualificados no pueden trabajar desde casa. Los pobres y vulnerables ${ }^{2}$ son los más afectados porque sus condiciones de vida y oportunidades futuras se ven amenazadas por las perturbaciones económicas y otros efectos negativos de la pandemia. A medida que el virus se propagó desde los distritos más ricos donde llegó primero, fue extendiéndose en el seno de las poblaciones que viven en unas condiciones sanitarias peores y sufren múltiples desventajas, que se magnifican debido al confinamiento.

La situación actual exige acciones urgentes en múltiples frentes relacionados: i) el frente epidemiológico, de atención sanitaria y saneamiento; ii) el frente económico; iii) el frente del mercado laboral, y iv) el frente de la protección social. Este trabajo se centra en un componente importante del frente de la protección social, que es identificar estrategias capaces de lograr tres objetivos para quienes viven en situación de pobreza y vulnerabilidad: i) reducir los riesgos epidemiológicos para salvar vidas; ii) proteger los medios de subsistencia, y iii) salvaguardar y asegurar la acumulación de capital humano. El objetivo de este documento es proporcionar un marco conceptual que oriente el diseño de las políticas.

El complejo vector de los trastornos derivados de la pandemia reduce los ingresos de la mayoría de las personas. Entre otras cosas, para determinados umbrales de pobreza, hará aumentar el número de personas pobres en las estadísticas oficiales. Un informe reciente de la Comisión Económica para América Latina y el Caribe (CEPAL) estima que el número de "nuevos pobres" será del orden de 45 millones de personas (CEPAL, 2020b). Las actuales medidas macroeconómicas y de otro tipo intentan -o deberían intentar- suavizar la presión a la baja sobre la curva de ingresos. Se destinan -o se deberían destinardistintas medidas a amortiguar el impacto en el empleo y los ingresos de muchas personas afectadas y, en particular, de las personas que corren el riesgo de caer en la pobreza. Sin embargo, aquellos que ya eran pobres corren el peligro de sufrir grandes pérdidas de ingresos, que en algunos casos los llevarían a vivir por debajo del umbral de la pobreza extrema. Según la CEPAL, cerca de 29 millones de personas podrían engrosar las filas de los que viven en la pobreza extrema en 2020 como consecuencia de la pandemia (CEPAL, 2020b). Sin duda, los pobres deben tener prioridad en lo que respecta al apoyo a los ingresos, pero eso no será suficiente para proteger de modo eficaz sus vidas, sus medios de subsistencia y su capital humano. Estas personas, los pobres crónicos, no solo sufren escasez de ingresos. También

\footnotetext{
1 Este documento se basa en una versión más extensa (véase Lustig y Tommasi (2020)), que incluye todo el conjunto de materiales de apoyo y referencias. Entre otras cosas, el presente documento incluye actualizaciones para reflejar los rápidos cambios que ha sufrido la región como resultado de la enfermedad por coronavirus (COVID-19). Nos gustaría agradecer a Mart Trasberg su ayuda en esta tarea.

2 A veces en la bibliografía económica, la palabra "vulnerable" se usa para referirse a personas cuyos ingresos están por encima del umbral de la pobreza, pero que corren el riesgo de caer en la pobreza si sufren una adversidad. Aquí no usamos el término de esa manera, sino en el sentido estándar del diccionario, de una persona que necesita atención, apoyo o protección especiales debido a su edad, discapacidad o riesgo de sufrir malos tratos o abandono.
} 
suelen vivir en hogares hacinados, carecen de los servicios sociales básicos, reciben poca atención médica y educación, y sufren diversas formas de discriminación. Este grupo incluye a los residentes de barrios marginales urbanos y otras zonas donde se concentra la pobreza, los migrantes indocumentados y las comunidades indígenas. Dentro de estos grupos, los niños, las mujeres, las personas mayores, las personas con capacidades diferentes y las del colectivo de lesbianas, gais, bisexuales, transgénero, queer e intersexuales (LGBTQl) se enfrentan a desafíos aún mayores.

Es fundamental que la respuesta política preste especial atención a las personas pobres y en situaciones vulnerables, por tres motivos principales. En primer lugar, como este grupo ya sufre múltiples desventajas, existe el imperativo ético de priorizar sus necesidades, ya que se trata de las personas que menos pueden permitirse verse afectadas por las muchas consecuencias negativas derivadas de la pandemia. En segundo lugar, los efectos negativos sobre este grupo probablemente tendrán repercusiones durante mucho tiempo. La bibliografía moderna sobre el desarrollo enfatiza los efectos permanentes que las perturbaciones temporales pueden tener en la vida de los bebés, los niños, los adolescentes y las mujeres. Las circunstancias como la malnutrición infantil, el abandono escolar y las experiencias traumáticas en algún momento de la vida suelen tener efectos irreversibles.

En una pandemia existe un tercer motivo fundamental para dar prioridad a quienes viven en la pobreza y en situaciones vulnerables. A medida que el virus se propaga rápidamente, las personas con realidades cotidianas más precarias no solo tienen un mayor riesgo de contraer la infección, sino que, además, son una fuente plausible de transmisión. Si no se compensa a estos grupos, al menos parcialmente, por su pérdida de ingresos durante los confinamientos, les resultará muy difícil cumplir las restricciones. Si las pruebas o la eventual vacuna no están ampliamente disponibles y son gratuitas (o tienen un coste muy bajo), es probable que los pobres y vulnerables decidan no hacerse la prueba o no vacunarse. Esta externalidad es uno de los principales argumentos a favor de priorizar estos grupos en el contexto de una pandemia. Durante la pandemia, "olvidarse" de proteger a determinados sectores de la sociedad (como los habitantes de barrios marginales, las personas sin hogar, los migrantes indocumentados o la población transexual, por nombrar solo algunos) puede perjudicar gravemente la capacidad de contener la propagación del virus. Durante una pandemia, la protección social universal se convierte en una condición necesaria para combatir con éxito la propagación de la enfermedad.

\section{El COVID-19 exacerba las desigualdades y vulnerabilidades preexistentes}

\section{Los grupos que corren el riesgo de contagiarse, enfermar y morir}

Si bien el número inicial de contagios y muertes en la región fue relativamente bajo, América Latina se ha convertido ahora en uno de los puntos críticos del COVID-19. En el momento de redactar este documento, la Argentina, el Brasil, Colombia, México y el Perú se encuentran entre los diez primeros países en términos de contagios; y el Brasil, Colombia, México y el Perú, entre los diez primeros en términos de muertes por cada 100.000 habitantes (CRC, 2020)․ Las personas mayores y aquellas con afecciones preexistentes son los dos grupos principales que corren el riesgo de contraer el COVID-19 y sucumbir. En cuanto a la edad, la proporción de personas mayores en la población de América Latina no es grande (menos del 9\%) (CEDLAS/Banco Mundial, 2020). En cuanto a las

\footnotetext{
3 Asimismo, de acuerdo con las proyecciones del Instituto de Sanimetría y Evaluación Sanitaria (IHME) publicadas el 25 de junio de 2020, se estima que, a 1 de octubre, el total de muertes por COVID-19 en América Latina y el Caribe llegaría a casi 440.000 (IHME, 2020).
} 
afecciones preexistentes, sin embargo, la situación es preocupante. El sobrepeso y la obesidad son muy prevalentes en América Latina (casi el 60\% de la población), y el 10\% de la población padece diabetes (OPS, 2020). Además, las deficientes condiciones sanitarias en los barrios marginales y otros barrios pobres de América Latina los convierten en lugares de especial preocupación.

\section{Múltiples privaciones}

Según el indicador internacional de la pobreza de 5,50 dólares de los Estados Unidos al día (expresado en términos de paridad del poder adquisitivo), la tasa de pobreza en América Latina antes del COVID-19 era del 23\%. Casi el $4 \%$ de los latinoamericanos vivían en la pobreza extrema (es decir, en el umbral de la pobreza de 1,90 dólares al día o menos) y no ganaban lo suficiente para comprar la cantidad mínima de alimentos para una nutrición adecuada. En América Latina, el 10\% de la población (definida según el umbral de la pobreza de 3,20 dólares al día) corría el riesgo de caer en la pobreza extrema. Este porcentaje era considerablemente mayor en algunos países de América Latina, como el Estado Plurinacional de Bolivia, Guatemala y el Ecuador (CEDLAS/Banco Mundial, 2020; CEPAL, 2020a).

Sin embargo, la pobreza asociada a los ingresos es solo la punta del iceberg en la vida de los pobres crónicos. Para la mayoría de la población en cuestión, la pobreza es una condición de vida que supone desventajas en múltiples ámbitos. Más del $80 \%$ de las personas en el quintil más pobre de la distribución de los ingresos trabajan en el sector informal y, por lo tanto, no tienen acceso a un seguro de desempleo, pensiones contributivas ni otras prestaciones. En América Latina, el 22\% de las personas carecen de acceso a agua potable segura; el 34\% no disponen de conexión a Internet, tan imprescindible en estas circunstancias, y el $45 \%$ no tienen cuenta bancaria. Si bien el grado de pobreza es más elevado en las zonas rurales, aproximadamente dos terceras partes de los pobres viven en zonas urbanas. Este parece ser el sector más afectado por la pandemia. Más del 20\% de los residentes urbanos viven en barrios marginales, donde las condiciones de hacinamiento y de hábitat deficiente son extremas (CEDLAS/Banco Mundial, 2020; CEPAL, 2020a).

\section{La perturbación generada por el COVID-19 interactúa con las desigualdades y las vulnerabilidades existentes}

Todas las desventajas mencionadas anteriormente que dan lugar a una pobreza multidimensional interactúan con las condiciones generadas por la pandemia y crean lo que puede llegar a ser un círculo vicioso. Muchas de estas vulnerabilidades hacen que las personas sean más propensas a contraer el coronavirus, y muchos de los efectos de la pandemia agravan el sufrimiento ocasionado por las privaciones.

Por ejemplo, vivir en barrios marginales hace que las personas sean más susceptibles a las infecciones y enfermedades graves debido al hacinamiento y a no tener acceso a agua y saneamiento. El mercado laboral informal es un aspecto clave de la vida de las personas pobres y vulnerables, y amplifica los efectos de la gran disminución de los ingresos que ha ocasionado la pandemia, especialmente para las personas que poseen pocos o ningún activo. En la mayoría de los países de la región, los trabajadores del sector informal no tienen ninguna protección social. No solo es poco probable que los pobres tengan un trabajo que se pueda realizar a distancia, sino que, además, les sería difícil hacerlo dadas las condiciones de sus hogares y la falta de infraestructura (como la conexión a Internet) ${ }^{4}$. Esto condiciona la posibilidad de "quedarse en casa". Si los pobres carecen de los medios para satisfacer sus necesidades básicas a corto plazo, no pueden seguir las reglas del aislamiento social. No pueden quedarse en casa si eso les impide obtener su sustento diario.

\footnotetext{
4 Lo mismo vale para la escolarización. Las desventajas educativas que sufren los niños pobres están empeorando, ya que se encuentran aislados en sus hogares sin conexión, con unos padres carentes de educación.
} 
Quedarse en casa significa soportar una serie de penurias provocadas por el hacinamiento, la falta de servicios básicos y los entornos deficientes donde se encuentran las viviendas. Además, es menos probable que estas familias tengan acceso a la educación y a fuentes de información fiables, ya que carecen de las herramientas necesarias para la conectividad. Quedarse en casa podría generar otros problemas de salud, especialmente teniendo en cuenta la situación actual del sector de la salud, en la que los problemas no relacionados con el coronavirus no reciben la atención adecuada. El confinamiento, el aburrimiento, la incertidumbre y el miedo asociados a las medidas de confinamiento podrían agravar la disfunción familiar que, en casos extremos, exacerba la violencia doméstica y el maltrato infantil.

Algunas de las principales dinámicas del círculo vicioso derivan del efecto combinado de las políticas de contención, y entre las repercusiones económicas se encuentran las que afectan al capital humano de los niños. En particular, es probable que la desnutrición en el útero y en las primeras etapas de la vida aumente como resultado de los ingresos más bajos. Además, es probable que el cierre de las escuelas afecte profundamente a los niños de hogares pobres, a quienes les puede resultar sumamente difícil (si no imposible) continuar con su educación desde casa a causa de la falta del equipo adecuado, la conectividad y, sobre todo, un tutor. Es muy probable que los niños terminen con un rendimiento más bajo y muchos podrían abandonar la escuela por completo. Este año puede acabar con la mayor pérdida de capital humano de la historia moderna. Esta pérdida se distribuirá de manera muy injusta, y los más vulnerables serán quienes padecerán más los efectos de este coste.

\section{Un breve perfil de los grupos vulnerables}

Como hemos dicho en la introducción, nuestro objetivo es proporcionar un marco conceptual para dar una respuesta política eficaz con el fin de proteger la salud y las vidas, los medios de subsistencia y el capital humano de los pobres y vulnerables. Definir a los pobres de ingresos es sencillo: se considera pobre cualquier persona cuyos ingresos sean inferiores al umbral de pobreza del país. Ayudar a las familias que viven en la pobreza a hacer frente a la pérdida de ingresos durante la pandemia también es sencillo: los gobiernos deberían ampliar los programas existentes de transferencias de dinero en efectivo (o añadir nuevos). Por lo menos 15 Estados introdujeron nuevos programas de asistencia social durante los primeros meses del confinamiento y la mayoría también ampliaron los sistemas existentes.

Sin embargo, nosotros argumentamos que otras formas de privación -más allá de la falta de ingresos suficientes- requieren la misma atención. La violencia a manos de la pareja con quien se convive o la discriminación en el sistema de salud debido al color de la piel, la orientación sexual o el estado migratorio son desventajas que se han agravado durante la pandemia. Estos comportamientos disfuncionales no pueden combatirse simplemente con transferencias de efectivo. Asimismo, las dificultades de los niños pobres en los barrios marginales que continúan su educación durante los confinamientos tampoco se pueden resolver con transferencias de efectivo. Las transferencias de dinero en efectivo no producirán el tipo de acompañamiento que los niños necesitan para continuar con la educación en casa de modo eficaz. Por lo tanto, el diseño de una respuesta política eficaz debe pasar por la identificación de los grupos vulnerables y sus circunstancias particulares. A continuación proporcionamos una descripción general de algunos de los principales grupos vulnerables.

- Los pobres de las zonas urbanas. Los pobres de las zonas urbanas, especialmente los que viven en barrios marginales, viven en una situación de gran complejidad en términos del riesgo epidemiológico, sus medios de subsistencia, su capital humano y sus condiciones de vida. Estos se superponen con otros tipos de privaciones ${ }^{5}$. Se trata, en gran parte, de trabajadores informales, sin activos ni seguridad social. Viven en hogares hacinados, sin

\footnotetext{
5 Muchas de las condiciones que describimos aquí también se aplican a la pobreza rural.
} 
agua ni saneamiento. Una gran proporción de ellos no tienen acceso a Internet. Sufren problemas de salud preexistentes. La mayoría de ellos no tienen acceso al sistema bancario. Suele haber varias disfunciones en la familia que, durante un confinamiento, pueden magnificarse hasta llegar a la violencia doméstica y el maltrato infantil. Para este grupo, quedarse en casa es extremadamente difícil.

- Las mujeres. La mayoría de las mujeres pertenecen al sector de los servicios, que ha sido especialmente afectado por las medidas de distanciamiento físico. Las mujeres son las cabezas de familia de muchos hogares monoparentales, que corren un mayor riesgo, lo que hace que las mujeres sean más vulnerables a la inestabilidad financiera. En toda la región, las mujeres son responsables de la mayoría de las tareas domésticas, que en muchos casos han aumentado debido a la cuarentena. También son las principales víctimas de la violencia doméstica, y los malos tratos han empeorado, ya que la cuarentena ha obligado a las familias a encerrarse juntas, lo que ha hecho aumentar las tensiones entre los miembros del hogar. Además, surgen otras fricciones cuando las familias tienen dificultades para llegar a fin de mes. Incluso antes de la llegada del COVID-19, el 15\% de las mujeres latinoamericanas habían denunciado que sufrían violencia doméstica (ONU-Mujeres, 2020).

- Los niños. Hay más de 150 millones de niños en América Latina. Casi la mitad viven en la pobreza. Incluso sin hacer referencia a los casos extremos como los niños que viven en la calle, muchos de estos niños son extremamente vulnerables en circunstancias normales y, más aún, en este momento. Hay niños que pueden acabar solos si su único cuidador enferma o muere. Muchos niños ven empeorar sus condiciones de vida debido a los problemas de ingresos de sus padres. Un gran número de niños tienen dificultades asistenciales en las circunstancias actuales. La escolarización de los niños pobres queda interrumpida a causa del cierre de las escuelas. Muchos jóvenes sufren varios de estos riesgos y desventajas al mismo tiempo. Especialmente en el caso de los niños pequeños, cualquiera de estas situaciones temporales puede tener efectos permanentes.

- Las personas mayores. Además de tener la mayor probabilidad de morir de COVID-19, las personas mayores también destacan como grupo vulnerable desde una perspectiva social. Dependen en gran medida de otras personas, al no saber usar las herramientas tecnológicas o de comunicación. Algunas viven solas y tienen dificultades para obtener alimentos, asistencia médica y medicamentos a causa de los confinamientos.

- La población indígena. América Latina tiene casi 50 millones de habitantes que pertenecen a comunidades indígenas (de más de 500 etnias diferentes). Estas comunidades representan el $8 \%$ de la población total de la región, el 14\% de los pobres y el 17\% de las personas que viven en la pobreza extrema (Albertos, 2018). En cuanto a su relación con el mercado laboral, los indígenas suelen tener empleos precarios y poco cualificados. Las comunidades indígenas también tienen un acceso restringido a la educación y sufren de primera mano los efectos negativos del cambio climático. Además, tanto su acceso a los centros médicos y a un saneamiento básico como su situación general de salud son deficientes en comparación con los de las poblaciones no indígenas con características similares.

- Los migrantes. Los migrantes, especialmente los indocumentados, suelen sufrir marginación y discriminación. Tienden a trabajar en el sector de servicios -sobre todo, en la industria de la hostelería-, que se ha visto especialmente afectado. A menos que sean residentes permanentes de larga duración, los migrantes no tienen derecho a beneficiarse de las transferencias de efectivo ni de otros programas. Por lo tanto, cumplir los confinamientos se convierte en una tarea imposible, ya que no existe ninguna red 
de protección para estos grupos. Eso es problemático porque justamente estos grupos se convierten en portadores naturales de la enfermedad y pueden desencadenar nuevos brotes. El problema se agrava porque, en algunos países, los migrantes indocumentados no tienen acceso al sistema de salud.

- Otros grupos vulnerables. La población "olvidada" y excluida también incluye otros grupos, como las personas sin hogar, la población reclusa, las personas que realizan trabajo sexual y las personas transexuales. Al diseñar políticas para contener la propagación del virus y mitigar el impacto de la consiguiente crisis económica, los responsables de formular políticas deben ser lo más inclusivos posible. El principio rector fundamental debe ser el indicado en la introducción: la protección social universal (en un sentido multidimensional) como requisito previo para combatir con éxito la propagación de la enfermedad.

\section{El impacto de las medidas de confinamiento en las personas que viven en situaciones de pobreza y vulnerabilidad}

\section{Ingresos}

Si bien no hay datos oficiales sobre el efecto del COVID-19 en la pobreza y la desigualdad, las microsimulaciones nos dan una idea de las posibles repercusiones. Lustig y otros (2020) calculan el impacto de las políticas de confinamiento originadas por el COVID-19 en la Argentina, el Brasil, Colombia y México. Las medidas de confinamiento tienen una gran repercusión en la pobreza de ingresos: el aumento del número de personas que viven en la pobreza en esos cuatro países (sin tener en cuenta la asistencia social) varía de 23,3 a 30,4 millones, dependiendo de las hipótesis. Los autores no suponen que las pérdidas de ingresos son proporcionalmente iguales en todos los tramos de la distribución de los ingresos, lo que hace que el efecto simulado sea mayor que en algunas estimaciones anteriores. A diferencia de lo esperado, Lustig y otros observan que los peores efectos no se producen en los más pobres, sino en las personas que ocupan (aproximadamente) una posición intermedia en la escala de distribución de los ingresos. Esto se debe a que las políticas de asistencia social implementadas por la mayoría de los países latinoamericanos en los últimos 25 años amortiguan los efectos sobre la caída de ingresos de los más pobres. El análisis también muestra que la ampliación sustancial de la asistencia social existente o los programas completamente nuevos (Argentina y Brasil) podrían contrarrestar una parte significativa de la pobreza causada por la crisis 6.

\section{Privación multidimensional}

Para evitar que el virus se propague sin control -cuando no se dispone de la capacidad de hacer bien las pruebas, el rastreo y el aislamiento-, todos los países latinoamericanos han puesto en práctica confinamientos (cuarentenas) totales o específicos. Una encuesta realizada en barrios urbanos pobres de la Argentina y los breves informes elaborados por las oficinas en los países del Programa de las Naciones Unidas para el Desarrollo (PNUD) sobre otros 12 países aportaron unas primeras pruebas de los efectos de las medidas de confinamiento en los pobres y vulnerables (Kessler, 2020).

\footnotetext{
6 Estos países no obtienen tan buenos resultados cuando se tienen en cuenta los efectos a largo plazo del cierre de las escuelas sobre el capital humano, como se muestra en Lustig, Neidhöfer y Tommasi (2020).
} 
En primer lugar, 8 de los 13 países mencionaron cuestiones relacionadas con la salud entre las principales preocupaciones. Se han limitado los servicios habituales y existen obstáculos importantes para obtener medicamentos y recetas, tan necesarios. En segundo lugar, en 5 de los 13 países, el aumento de la violencia doméstica -tanto en las calles como dentro de los hogares- se mencionó entre las principales preocupaciones. Esta situación se ve agravada por el elevado consumo de alcohol y drogas.

En tercer lugar, se constata que el acceso a los alimentos es uno de los principales problemas. Las tiendas de comestibles de los barrios frecuentadas por la población pobre carecen de una oferta adecuada, y a esto se le suman los grandes aumentos de precio y la disminución de los ingresos. Es difícil para las organizaciones no gubernamentales (ONG), las iglesias y otros actores sociales locales mantener en funcionamiento sus actividades habituales en las circunstancias actuales. Entre los demás problemas que se detectaron se encuentran la discriminación y la exclusión de minorías, migrantes y miembros de la comunidad LGBTQl; el hacinamiento, y el acceso desigual al aprendizaje en línea.

Las clases virtuales no están disponibles para todo el mundo, ya que los servicios de conexión se distribuyen de manera desigual en estos barrios. Dado que los jóvenes no han podido comenzar adecuadamente el año académico, su situación ha empeorado. El abandono escolar es un fenómeno frecuente y estas circunstancias temporales pueden tener efectos permanentes para los niños y adolescentes marginados de la sociedad.

Existen ciertas pruebas del impacto del COVID-19 en otros ámbitos no relacionados con los ingresos, como la nutrición, la salud, la matriculación escolar y los resultados del aprendizaje. El Programa Mundial de Alimentos (PMA, 2020) calcula que el número total de personas en situación de inseguridad alimentaria grave podría aumentar y pasar de 3,4 millones en 2019 a unos 16 millones en 2020 debido al COVID-19 en la región. Los programas de alimentación escolar son un componente crucial de las políticas para garantizar el derecho a la alimentación, y se estima que, debido al cierre de las escuelas, se ha visto afectada la forma habitual de obtención de alimentos de 65 millones de escolares (FAO/CEPAL, 2020). Mientras que, antes de la pandemia, se esperaba que los niños completaran 7,7 años de escolarización en América Latina y el Caribe, las simulaciones realizadas por Azevedo y otros (2020) sugieren que los confinamientos podrían reducir la escolarización a los 7,4 años en el escenario optimista (se cierran las escuelas durante tres meses de un año escolar de diez meses) y a los 6,8 años en el escenario pesimista (se cierran las escuelas durante siete meses). En el marco del Programa para la Evaluación Internacional de los Alumnos (PISA), se espera que la puntuación media en la región disminuya de 402 a 396 en el caso optimista, y a 376 en el pesimista.

\section{El diseño y la ejecución de una respuesta eficaz}

Este apartado describe las recomendaciones institucionales para diseñar y ejecutar una respuesta política eficaz. También presenta recomendaciones de políticas específicas, muchas de las cuales ya se están probando en la región.

\section{Recomendaciones institucionales}

Como se ha planteado anteriormente, muchas comunidades y colectivos latinoamericanos sufren varias desventajas simultáneamente. En otras palabras, sufren pobreza multidimensional. Estas situaciones preexistentes se ven agravadas por la pandemia del COVID-19, que pone en peligro no solo sus vidas y medios de subsistencia, sino también su capital humano. La teoría moderna del desarrollo humano reconoce que durante la vida de las personas se producen acontecimientos críticos que podrían 
afectarlas para siempre, como un incendio en su casa, la muerte de un miembro de la familia, una atención médica inadecuada durante el embarazo, la malnutrición infantil, experiencias traumáticas, un embarazo adolescente, la violencia doméstica, el consumo de drogas y el abandono escolar. Habida cuenta de la existencia de múltiples dimensiones de la privación que se refuerzan recíprocamente y en vista del riesgo de tales acontecimientos perturbadores a lo largo de la vida, es tremendamente importante -en épocas normales e incluso más en la emergencia actual- que las intervenciones públicas consigan centrarse en ayudar a estos grupos vulnerables de la población. Para las personas más vulnerables, las políticas generales impuestas desde arriba no son suficientes. Deben ir acompañadas de esfuerzos coordinados que se centren en los riesgos específicos que sufren cada comunidad, cada familia y cada persona. Expresado en la jerga de las políticas públicas, la coordinación entre los sectores gubernamentales y la priorización de las circunstancias individuales y locales son esenciales.

La pregunta es cuál es la mejor manera de lograr tal coordinación y priorización desde el punto de vista organizativo. Hay dos funciones institucionales esenciales que deben llevarse a cabo para diseñar e implementar de modo eficaz políticas dirigidas a los más vulnerables. En primer lugar, debe haber una proximidad física y social con las comunidades vulnerables para contar con su confianza y para mediar entre las necesidades específicas de la comunidad (y las familias y las personas) y el conjunto amplio y desorganizado de programas públicos. En segundo lugar, debe haber una capacidad de coordinación o de persuasión suficiente en lo que respecta a los organismos centrales, los ministerios y los programas para que atiendan a las necesidades particulares de una comunidad específica.

Estas funciones institucionales las podrían desempeñar distintas estructuras gubernamentales. Varios países de América Latina cuentan con unidades gubernamentales que, en cierta medida, están en consonancia con esta lógica. Sin embargo, en términos generales, son necesarios dos pasos: primero, identificar qué estructuras gubernamentales existentes desempeñan mejor estas funciones y, segundo, dotarlas de los recursos adecuados y el respaldo político al más alto nivel (la Oficina de la Presidencia en la mayoría de los países latinoamericanos).

En la versión más larga de este artículo, detallamos los actores, las funciones y las recomendaciones en varios niveles, desde las más altas instancias del gobierno hasta sobre el terreno. En aras de la brevedad, mencionaremos las funciones que corresponden a tres capas cruciales: i) el organismo responsable de ayudar a las poblaciones más vulnerables; ii) las unidades territoriales pertinentes en cada comunidad y barrio pobre, y iii) las redes y las organizaciones locales implicadas en la implementación a nivel comunitario.

i) Idealmente, la coordinación de todas las medidas del Estado diseñadas para prestar apoyo social a los barrios y comunidades pobres debería recaer en un organismo responsable de esta tarea. Este organismo debería ajustar todas las políticas generales (difusión de información, control de epidemias, transferencias de ingresos, alimentación, salud, seguridad y educación) a las necesidades particulares de estas comunidades. Debería exigir que los ministerios pertinentes implementaran las medidas adicionales necesarias. Un ejemplo sería la impartición de educación para las poblaciones con un acceso limitado a Internet. Un organismo de este tipo también debería coordinar las unidades territoriales en cada barrio. A través de las unidades territoriales, la entidad debería recabar información sobre las necesidades generales y específicas de estas poblaciones.

ii) Las principales tareas de las unidades territoriales dentro de cada barrio pobre son las siguientes:

- Coordinar la implementación local de todas las intervenciones a nivel nacional y local.

- Involucrar a las redes vecinales y las organizaciones locales (ONG, iglesias y movimientos sociales) en la identificación de las urgencias y prioridades específicas.

- Fortalecer las redes de actores sociales locales. 
iii) La participación de los agentes locales de base es fundamental para garantizar que las intervenciones sean eficaces y estén bien dirigidas. Las intervenciones monetarias y no monetarias son cruciales para quienes viven en situación de pobreza y vulnerabilidad. Entre estas, se encuentran la obtención de alimentos, ropa, asistencia médica y educativa, y el apoyo emocional, por citar solo algunas. Los organismos estatales deben contar con actores locales que sean conscientes de las necesidades específicas de cada niño, madre adolescente, joven en situación de riesgo y superviviente de la violencia doméstica, y saber cuándo se necesita esa ayuda esencial.

Añadimos una cuarta recomendación relacionada con la asignación de recursos.

iv) Todas las acciones propuestas tienen importantes implicaciones presupuestarias. La terrible situación actual requiere una reasignación de recursos valiente. Nuestra reivindicación principal al respecto es que debemos asignar más recursos para proteger las vidas, los medios de subsistencia y el capital humano de los más pobres. Con respecto a las recomendaciones institucionales de este apartado, esto implica:

- asignar más recursos a las unidades gubernamentales que se centran en los más vulnerables, y

- canalizar parte de la distribución de las ayudas y los servicios a través de ONG y organizaciones sociales de base, y asignarles el presupuesto necesario.

Debemos añadir que, aunque se necesitan recursos presupuestarios, parte de estos objetivos pueden cumplirse con decisiones políticas y visión institucional ${ }^{7}$.

\section{Recomendaciones concretas}

Además de las recomendaciones generales mencionadas anteriormente, este apartado incluye un conjunto de recomendaciones concretas para varias etapas del ciclo de la pandemia. Las clasificamos en dos categorías principales: reducción de la exposición al riesgo epidemiológico, y protección de los medios de subsistencia, el capital humano y la prestación de servicios básicos.

\section{a) Reducción de la exposición al riesgo epidemiológico de enfermar y morir}

\section{Durante el estado de emergencia:}

- Diseñar estrategias de comunicación adecuadas. Las campañas de información deben ser lo más transparentes posible y ajustarse a las realidades del público objetivo.

- Planificar estrategias que impliquen a grupos marginados en zonas urbanas y a comunidades indígenas. Las autoridades deben impedir que el virus se propague y, al mismo tiempo, evitar cualquier tipo de discriminación.

- Garantizar el acceso a agua limpia, jabón y otros productos esenciales -como mascarillasque son necesarios para la prevención.

- Garantizar el acceso a ingresos, alimentos y la satisfacción de las necesidades básicas. Es crucial para que las restricciones que obligan a quedarse en casa sean viables.

\footnotetext{
7 Implementar estas medidas con éxito es menos caro de lo que podría parecer. Se necesita una acción política enérgica y decidida para cambiar algunos incentivos burocráticos. Esto es aplicable a varias políticas aparte de las transferencias de efectivo, como la protección de las mujeres de la violencia doméstica o las intervenciones específicas para evitar la malnutrición infantil.
} 
- Garantizar la conectividad en zonas marginadas. Es esencial para que las personas puedan comunicarse con las redes de apoyo en tiempo real, denunciar actos de violencia o delitos, ofrecer actividades alternativas a los niños y jóvenes y, en algunos casos, facilitar algunas actividades que generan ingresos. Esto podría incluir proporcionar equipos a representantes clave dentro de la comunidad.

- Utilizar espacios que no sean hospitales, como escuelas u hoteles, para aislar correctamente a los pacientes con COVID-19 o aquellos que presenten síntomas similares.

- Diseñar estrategias para trasladar de forma segura a los pacientes que necesitan atención médica especial de un centro médico a otro. Esto significa que se deberían invertir fondos adicionales en el transporte, por ejemplo, en ambulancias, especialmente en las zonas rurales.

Después del estado de emergencia:

- Dar acceso gratuito a las pruebas del COVID-19 a los grupos más pobres y vulnerables de la sociedad.

- Seguir abriendo nuevos centros de aislamiento para permitir que las personas que puedan estar infectadas se aíslen.

- Garantizar el acceso a agua potable segura.

- Asegurarse de que los grupos marginados posean dispositivos tecnológicos para poder rastrearlos. Esto contribuirá a evitar un nuevo repunte de los casos de COVID-19, así como a mejorar la comunicación integral gracias a la conectividad.

- Promover la inclusión financiera basada en las tecnologías de la información y las comunicaciones (TIC). Proporcionar acceso a servicios bancarios y tarjetas de débito no solo hará que las transferencias sean más eficientes, sino que también dará a las autoridades una perspectiva interna del impacto económico del brote del virus.

\section{b) Protección de los medios de subsistencia, el capital humano y la prestación de servicios básicos}

\section{Acceso a ingresos, alimentos y servicios}

- Transferencias. Recomendamos realizar transferencias monetarias que permitan a las personas pobres alcanzar un nivel mínimo de consumo, especialmente en el caso de las personas no cubiertas por los sistemas anteriores. Otra alternativa es el uso de cupones para alimentos (más recientemente, tarjetas de débito, que se usan para comprar alimentos).

- Programas de empleo temporal. Recomendamos contratar a la población activa actualmente desempleada para realizar tareas que requieran unas habilidades similares en los sectores que tengan una gran demanda en la actualidad, como desinfectar vehículos de transporte o espacios públicos, custodiar y prestar diversos servicios a hospitales y médicos, o trabajar en la distribución de alimentos.

- Distribución directa de alimentos. Se debe prestar atención a la optimización de los protocolos y materiales para minimizar el contacto humano. Debería hacerse mediante el apoyo de las organizaciones de base existentes.

- Recortes fiscales o aplazamientos del pago de impuestos. Por ejemplo, deberían eliminarse temporalmente los impuestos sobre transferencias o remesas internacionales (por debajo de cierta cantidad). 
- Prevención de la interrupción de los servicios básicos, como agua, electricidad y wifi, a los hogares vulnerables.

Mitigación de la violencia doméstica. Deberían diseñarse y ejecutarse rápidamente políticas adicionales que se ocupen de la violencia doméstica. Deben implementarse procedimientos estándar para identificar y prevenir episodios violentos. Por ejemplo, se debe garantizar a las víctimas el acceso a espacios confidenciales para alertar a las autoridades. Aquí, de nuevo, las organizaciones de base y las redes locales deberían ser actores clave, y los funcionarios de los gobiernos locales deben responsabilizarse de poner en marcha soluciones rápidas.

Continuación de la educación. La educación debe continuar a través de la televisión o de la radio si la conectividad no es una opción para algunas familias. Las empresas de comunicación deben empezar a ofrecer paquetes especiales como parte de sus servicios para poder disponer de los servicios de Internet inalámbrico gratuitos o subvencionados con fines educativos. Las estrategias para aliviar las restricciones deben centrarse en los niños vulnerables al margen de la sociedad.

Acceso garantizado a la salud y los medicamentos más allá del COVID-19. Es esencial contar con unos protocolos adecuados para aislar a los pacientes con posibles síntomas de COVID-19. Sin embargo, también deben seguir prestándose los servicios vitales habituales de la atención sanitaria, como las vacunaciones, el tratamiento de enfermedades infecciosas, la atención de los aspectos de salud sexual y reproductiva (por ejemplo, los métodos anticonceptivos), los medicamentos para enfermedades crónicas y mentales, las intervenciones quirúrgicas de urgencia y la atención a las víctimas de violencia y accidentes. Deberían aumentarse los servicios que ofrecen las unidades de atención primaria existentes en los barrios, y ampliarse su horario de funcionamiento.

Consideración de los grupos particularmente vulnerables. El impacto de las crisis como esta es el doble de devastador para los grupos que, además de vivir en la pobreza, tienen problemas o riesgos específicos, como los niños, los jóvenes en situaciones de riesgo, los migrantes indocumentados y las personas transexuales, sin hogar o en prisión. En toda América Latina, algunas organizaciones sin ánimo de lucro desempeñan un papel clave para aliviar y resolver sus dificultades. Se deben apoyar y promover esas acciones.

\section{Observaciones finales}

Habida cuenta de las interconexiones entre las diversas dinámicas de la pandemia, es crucial integrar las estrategias epidemiológicas, económicas y sociales en un marco general coherente. Debería priorizarse el bienestar de los más pobres y más vulnerables de la sociedad, con los tres objetivos de preservar las vidas, los medios de subsistencia y el capital humano. Esto es imprescindible no solo por motivos humanitarios, sino también para minimizar el impacto de las externalidades epidemiológicas y económicas, así como los riesgos sociales y políticos. Los grupos más pobres y más vulnerables requieren una atención especial no solo en cuanto al apoyo a los ingresos, sino también en todo el conjunto de acciones destinadas a mejorar su bienestar general. Es esencial complementar las políticas generales (salud, educación, seguridad y conectividad) con acciones especiales dirigidas a los grupos vulnerables. Esto requiere una acción urgente a corto plazo, así como inversiones estratégicas a medio plazo. A corto plazo, es crucial mantener el acceso a los ingresos, los alimentos y la atención sanitaria, así como llevar a la práctica acciones decisivas para prevenir las consecuencias negativas de la pandemia (como el aumento de la violencia, sobre todo, la violencia doméstica). A medio plazo, es 
fundamental invertir en servicios de conectividad y definir acciones para asegurarse de que los niños pobres puedan recuperar la formación perdida y no abandonen la escuela.

Al diseñar intervenciones, es decisivo tener en cuenta las especificidades y los niveles de heterogeneidad entre los grupos vulnerables y dentro de ellos. Para ello, es importante aprovechar las redes sociales locales y colaborar con los actores no gubernamentales que trabajan muy próximos a estos grupos.

\section{Bibliografía}

Albertos, C. (2018), "Desarrollo sostenible de los pueblos indígenas: con ellos, para ellos”, Mejorando Vidas, Banco Interamericano de Desarrollo (BID) 9 de agosto [en línea] https://blogs.iadb.org/igualdad/es/ desarrollo-sostenible-de-los-pueblos-indigenas-con-ellos-para-ellos/.

Azevedo, J. P. y otros (2020), "Simulating the potential impacts of COVID-19 school closures on schooling and learning outcomes: a set of global estimates", Policy Research Working Paper, № 9284, Washington, D.C., Banco Mundial.

CEDLAS (Centro de Estudios Distributivos, Laborales y Sociales)/Banco Mundial (2020), Base de Datos Socioeconómicos para América Latina y el Caribe (SEDLAC), mayo [en línea] https://www.cedlas.econo. unlp.edu.ar/wp/estadisticas/sedlac/.

CEPAL (Comisión Económica para América Latina y el Caribe) (2020a), CEPALSTAT [base de datos en línea] https://estadisticas.cepal.org/cepalstat/Portada.html.

(2020b), "Enfrentar los efectos cada vez mayores del COVID-19 para una reactivación con igualdad: nuevas proyecciones", Informe Especial COVID-19, N 5, Santiago, julio.

CRC (Coronavirus Resources Center) (2020), "Mortality analyses", Johns Hopkins University \& Medicine [en línea] https://coronavirus.jhu.edu/data/mortality.

FAO/CEPAL (Organización de las Naciones Unidas para la Alimentación y la Agricultura/Comisión Económica para América Latina y el Caribe) (2020), "Sistemas alimentarios y COVID-19 en América Latina y el Caribe: hábitos de consumo de alimentos y malnutrición", Boletín, № 10, julio [en línea] https://repositorio.cepal. org/bitstream/handle/11362/45794/1/cb0217_es.pdf.

IHME (Instituto de Sanimetría y Evaluación Sanitaria) (2020), "Correction: new IHME COVID-19 model forecasts Latin American, Caribbean nations will see nearly 440,000 deaths by October 1", 25 de junio [en línea] http://www.healthdata.org/news-release/correction-new-ihme-Covid-19-model-forecasts-latin-americancaribbean-nations-will-see.

Kessler, G. (coord.) (2020), Relevamiento del impacto social de las medidas del aislamiento dispuestas por el PEN, Buenos Aires, Comisión de Ciencias Sociales, Unidad Coronavirus COVID-19, marzo.

Lustig, N. y M. Tommasi (2020), El COVID-19 y la protección social de los grupos pobres y vulnerables en América Latina, Buenos Aires, Centro de Estudios para el Desarrollo Humano (CEDH) de la Universidad de San Andrés/Commitment to Equity Institute (CEQI) de la Universidad de Tulane, mayo.

Lustig, N., G. Neidhöfer y M. Tommasi (2020), "Short and long-run distributional impacts of COVID-19 in Latin America", CEQ Working Paper series, No 96, Commitment to Equity (CEQ) Institute, Tulane University, octubre.

Lustig, N. y otros (2020), "The impact of COVID-19 lockdowns and expanded social assistance on inequality, poverty and mobility in Argentina, Brazil, Colombia and Mexico", Covid Economics, Vetted and Real-Time Papers, № 46, Centro de Investigación en Economía y Política (CEPR), septiembre.

ONU-Mujeres (Entidad de las Naciones Unidas para la Igualdad de Género y el Empoderamiento de las Mujeres) (2020), "COVID-19 and ending violence against women and girls", EVAW COVID-19 Briefs, Nueva York, mayo.

OPS (Organización Panamericana de la Salud) (2020), Plataforma de Información en Salud para las Américas (PLISA) [base de datos en línea] https://www.paho.org/data/index.php/es/.

PMA (Programa Mundial de Alimentos) (2020), "El hambre aumenta a medida que los casos de la COVID-19 se disparan en América Latina", Roma, 29 de julio [en línea] https://es.wfp.org/noticias/hambre-aumentaa-medida-casos-covid-19-se-disparan-America-Latina-Caribe. 